\title{
ATP consumption in molecular reactions of neuronal signaling
}

\author{
Nikon Rasumov ${ }^{*}$, Erik De Schutter \\ From The Twenty Third Annual Computational Neuroscience Meeting: CNS*2014 \\ Québec City, Canada. 26-31 July 2014
}

The human brain consumes $10^{6}$ times less energy than the currently fastest supper computer [1], while maintaining a comparable performance in many demanding task [2]. These energetic efficiency has been suggested to result from primitive computations on a molecular level [3]. However, while the importance of ion channels on energy efficiency has been the primary focus of research [4,5], most computations occur at the molecular level prior to the amplification step and prior to the information transmission. We calculate the amount of energy consumed by such computations and compare their structural and functional properties. As a starting point, we chose the molecular reactions involved in long term depression and using our stochastic model [6] estimate the molecular energy consumption. To compare our feedback loop we investigate the energy consumption of millions of feedback loops in molecular signaling. For the first time we are able to go beyond the current size limit of 15 steps [7] and, using a computer cluster, detect feedback loops with hundreds of molecular reactions. We find that the number of ATPs consumed is related with size of positive feedback loop. We conclude that the energy consumed by the long term depression is only marginally above the physical limit of storing information and higher than its silicon equivalent of random access memory. Hence, this study provides the first systematic attempt to investigate the energy consumption of information-storing primitive computations and points towards energy efficient motifs for synthetic biology.

\section{Acknowledgements}

Both are funded by OIST GU, Japan.

\footnotetext{
* Correspondence: nikon@oist.jp

Okinawa Institute of Science and Technology, 1919-1 Tancha Onna-son,
} Okinawa, 904-0495 Japan

\section{Biomed Central}

(0) 2014 Rasumov and De Schutter; licensee BioMed Central Ltd. This is an Open Access article distributed under the terms of the Creative Commons Attribution License (http://creativecommons.org/licenses/by/4.0), which permits unrestricted use, distribution, and reproduction in any medium, provided the original work is properly cited. The Creative Commons Public Domain Dedication waiver (http://creativecommons.org/publicdomain/zero/1.0/) applies to the data made available in this article, unless otherwise stated.
Published: 21 July 2014

\section{References}

1. Niven JE, Laughlin SB: Energy limitation as a selective pressure on the evolution of sensory systems. Journal of Experimental Biology 2008,

2. Ferrucci DA: Introduction to "This is Watson". Ibm Journal of Research and Development 2012, 56(3-4):15.

3. Mead C: Neuromorphic Electronic Systems. Proceedings of the leee 1990, 78(10):1629-1636.

4. Sengupta B, Stemmler M, Laughlin SB, Niven JE: Action Potential Energy Efficiency Varies Among Neuron Types in Vertebrates and Invertebrates.

5. Alle $H$, Roth A, Geiger JRP: Energy-Efficient Action Potentials in Hippocampal Mossy Fibers. Science 2009, 325(5946):1405-1408.

6. Antunes G, De Schutter E: A Stochastic Signaling Network Mediates the Probabilistic Induction of Cerebellar Long-Term Depression. J Neurosci 2012, 32(27).

7. Ma'ayan A, Cecchi GA, Wagner J, Rao AR, lyengar R, Stolovitzky G: Ordered cyclic motifs contribute to dynamic stability in biological and engineered networks. Proc Natl Acad Sci U S A 2008, 105(49):19235-19240.

doi:10.1186/1471-2202-15-S1-P179

Cite this article as: Rasumov and De Schutter: ATP consumption in molecular reactions of neuronal signaling. BMC Neuroscience 2014 15(Suppl 1):P179. 211(11):1792-1804 Plos Computational Biology 2010, 6(7). and take full advantage of:

- Convenient online submission

- Thorough peer review

- No space constraints or color figure charges

- Immediate publication on acceptance

- Inclusion in PubMed, CAS, Scopus and Google Scholar

- Research which is freely available for redistribution 